\title{
Unifying the classical approach with new technologies: An innovative proposal for teaching mathematics in engineering
}

\author{
Sergio Amat, Sonia Busquier, $M^{\mathrm{a}}$ José Legaz and Juan Ruiz \\ Universidad Politécnica de Cartagena, Universidad de Cádiz and Universidad de Alcalá
}

\begin{abstract}
The aim of this paper is to present a teaching experience developed in the Polytechnic University of Cartagena and, more specifically, in the subject of Mathematical Methods Applied to Civil Engineering, that belongs to the Master Degree of Paths, Channels and Ports. Our classes were a mix between the traditional system and the new educational system. Moreover, we tried to adapt the evaluation process to the new European Framework for Higher Education. We have used videos developed by us and by students in our classes. We have noticed that the interest and motivation in class has grown. Also the grades have improved. We did a survey during this academic year and the results were strongly positive for both students and teachers.
\end{abstract}

Keywords - European Framework, higher education, new educational tool.

\section{INTRODUCTION}

$\mathrm{M}$ EDIA, and video in particular, are in a period of profound transition [1]. There are several reasons for this outstanding development of this technology, but three stand out. Technology has rendered many of the processes of media creation, distribution, and consumption faster and less costly than ever before. Public expectations about the availability of media have grown to the point that many people consume and freely exchange media each day in the course of their personal and professional life. New companies and enterprises regularly make use of videos in publicity in order to influence fashion or to introduce new products in the market. YouTube, by posting 13 hours of video every minute, is one of the most powerful tools used for this tasks. Wikipedia, that is about to make available videos in its entries, via the open-source codec Ogg [2], will be another big distributor of video contents. While a number of studies [3] have pioneered the progress in the field of understanding the use of the Internet and web resources in secondary education and everyday life, the time is right to take a careful look to the teaching and learning at the university level [4].

We describe our experience using videos to teach Mathematical Methods to students of master degree level at the Polytechnic University of Cartagena. This proposal could be classified halfway between the classical teaching techniques and the new pedagogical proposals introduced to adapt teaching methods to the new European Framework for Higher Education. The innovation is focused on the use of teaching videos developed by teachers themselves as a complement for classroom lessons. We try to study the effect of these videos on our students' grades.

In the paper, we attempt to describe our experience. First of all, we perform a description of the subject. Secondly, we present the type of evaluation followed and the grades obtained by students. After that, we show the teaching evaluation survey. Finally, we expose some conclusions.

\section{A Brief Description Of The Subject}

The course of Mathematical Methods applied to Civil Engineering is composed by a collection of lessons that are taught during the first semester of the first year of the Master Degree level of Paths, Channels and ports Engineering. The course has a total of 30 hours, divided in 24 hours of theory an 6 hours of computer practices. It is a continuation of the knowledge acquired by the students during the undergraduate period. The aim of the subject is to widen the mathematical knowledge and tools that the students already have, and that is necessary to tackle the study of the rest of the subjects of the master degree. This subject will help to form the scientific profile that will be needed to assure professional expertise in their field.

The different parts of the subject are the following:

1. Preliminaries: Complex variable, differential geometry, form operators, surface geometry.

2. Introduction to differential equations: First order differential equations. Linear equations and systems of equations. Numerical resolution of first order differential equations.

3. Partial differential equations: Introduction to partial differential equations. Linear partial differential equations of second order. Separation of variables to solve PDEs. Integral transforms to solve PDEs. Numerical methods for PDEs.

4. Statistics and optimization: Non linear optimization. Function approximation through linear and non linear mean squares.

Computer practices consist in the manipulation of MATLAB programs provided by the teachers of the subject. The blocks of this part are the following

1. Numerical resolution of differential equations.

2. Numerical resolution of partial differential equations.

3. Statistics and optimization.

The study of the subject is organized in the following way:

1. Preliminaries: The study of this introductory part is done by the students alone. In order to do this, they use the material and notes provided by the professors of the subject.

2. Introduction to differential equations and partial differential equations: This part of the subject is introduced using the classical big group class. Theory and problems are exposed using the blackboard and slides.

4. Statistics and optimization: This part of the subject is studied in groups of two or three people using the videos provided by the professors of the subject.

5. Computer practice: This part of the program is introduced during the classes at the computer lab. 


\section{Type Of Evaluation And GRAdING}

The evaluation was divided in four sections and was carried out through exams, where theoretical and practical questions are posed to students. The aim was to check the level acquired by the students and their capability to apply their theoretical knowledge to particular problems:

1. Preliminaries. This part was graded with a ten percent extra for the whole subject, that could be obtained in the first exam.

2. Introduction to differential equations: This part was graded with the thirty percent of the total.

3. Partial differential equations: This part was graded with the thirty percent of the total.

4. Statistics and optimization: This part was graded with the thirty percent of the total.

5. Matlab programming: This part was evaluated including section in each one of the previous exams. The aim was to evaluate the programming skills acquired by the students. The total grade for this part was the ten percent of the total.

The grades earned by the 16 students enrolled in 2007-2008 were:

- 1 First of the Class with Distinction (10 of 10).

- 9 A's $(9$ of 10$)$

- 13 B's (7 of 10

- $1 \mathrm{C}(5$ of 10$)$

Since the academic year 2005/2006, annual teaching-evaluation surveys have been carried out for all subjects at our university. Below we present the grades earned, on a scale from 0 to 5 . We only include the academic year 2014-2015:

- Teacher average grade for this subject: 4.3

- Degree average: 3.5

- We can see that the average for the subject is nearly one point above the mean of the degree.

\section{ANALYSIS AND CONCLUSIONS}

The teaching experience described is a hybrid between the classical teaching methods and innovative strategies, that are necessary to adapt the subjects to the new European Framework for Higher Education. The greatest innovation was the use of teaching videos for an important part of the subject and the opportunity to pass the subject preparing and exposing projects through workgroups. The results achieved by the students and reflected in the teaching evaluation of this subject have been very positive.

From this experience, we can highlight the following points:

- The exposed proposition is in continuous evolution. Every year we actualize and complete the database of videos. Next year we are planning to introduce virtual blackboards, in order to record the expositions of the students. We think that it can be very interesting to provide access to expositions of students performed in previous years.

- The combination of promoting self-teaching and the fact that students like new technologies, is a good explanation of why the proposition exposed has been so successful.

- We have promoted in a natural way working in groups and collaboration among students.

- The work done by students along the semester must be continuous. A direct consequence is that classes are more dynamic.

- The fact that students must prepare and explain to their fellows sections of the subject, impose them a deep analysis of the part that they have to expose. For this reason, we think that expositions in public are highly pedagogical. When students have to prepare an exposition in order to explain to others, they pay attention to details that would go unperceived if they only had to prepare an exam by solving exercises. What is more, they also have to express themselves in a correct mathematical way, that is something quite complicate for most of the students.

- Individual tutorial sessions to each group of students has proven to be very useful for both, the students and professors. On the one hand, we can detect points of weakness in their process of learning. On the other hand, we assure more control over the work the students are doing. These tutorial sessions in reduced groups. enhance the relation between students and instructors, allowing the students to fight against their usual lack of confidence and to ask everything they have not understood during classes. Also, these activities grant that the students will plan better their preparation to confront the evaluation.

- We think that the proposed structure of the subject is correct. Our philosophy is to tackle the teaching of the subject globally, but using different approaches. First of all, we explain each part of the subject. Then, the students must be capable of assimilating the matter making use of the mentioned explanations, videos provided, explanations of their fellows in public presentations and tutorial sessions.

- We have also started to introduce talks where people from different research groups of our university explain a topic related with the subject. These talks have a great acceptance by the students and we think that are the perfect complement to show particular applications of the field studied.

- Finally, we want to remark that our proposal provide the students with the time that is necessary to mature the ideas exposed. This is of great importance when teaching mathematics.

\section{REFERENCES}

[1] Starr, Paul: The Creation of the Media: Political Origins of Mass Communications (New York: Basic Books, 2004), at http://books.google. com/books?id=KO30kMoLKKkC; and Musser, Charles. The Emergence of Cinema: The American Screen to 1907 (Berkeley: University of California Press, 2000).

[2] http://www.washingtonpost.com/wpdyn/content/story/2008/07/03/ ST2008070304015.html and http://blog.wikimedia.org/2009/01/26/ mozilla-and-wikimedia-join-forces-to-support-open-video/

[3] http://www.pewinternet.org/reports.asp

[4] Kaufman ,P. and Mohan, J. (2009). Video Use and Higher Education: Options for the Future.

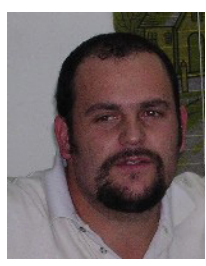

Sergio Amat Plata received the M.S., B.S., and Ph.D. degrees in mathematics from Universidad de Valencia, Valencia, Spain, in 1996 and 2001, respectively. Currently, he is Full Professor at the Department of Applied Mathematics and Statistics, Universidad Politécnica de Cartagena, Cartagena, Spain. His research interests include nonlinear reconstructions, multiresolution and wavelets algorithms, as well as iterative schemes for nonlinear equations and numerical approximation of differential equations.

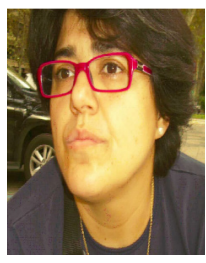

Sonia Busquier received the B.S. degree from Universidad de Valencia and her Ph.D. degree from Universidad Politécnica de Cartagena. Currently, she is Professor in the Department of Applied Mathematics and Statistics, Universidad Polit'ecnica de Cartagena, Cartagena, Spain. Her research interests include nonlinear reconstructions, multiresolution and wavelets algorithms, as well as iterative schemes for nonlinear equations. 


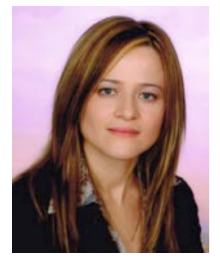

María José Legaz received her Ph.D. degree from Universidad Politécnica de Cartagena. Currently, she is Professor in the Universidad de Cádiz, Cádiz, Spain. Her research interests include variational techniques, ordinary differential equations, partial differential equations, extrapolation, as well as iterative schemes for nonlinear equations and numerical methods for PDE and ODE resolution.

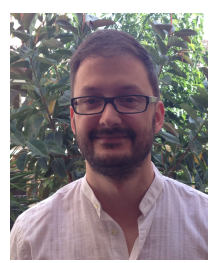

Dr. Juan Ruiz received his M.S., B.S. in Telecommunications Engineering in 2005 and his Ph. D. in Applied Mathematics in 2010 from Universidad Politécnica de Cartagena. He also received a B.S in Physics in 2014 from Universidad Nacional de Educación a Distancia. At the moment he holds a position as Assistant Professor at the Department of Physics and Mathematics, Universidad de Alcalá, Madrid, Spain. His research interests include nonlinear interpolation, subdivision and multiresolution methods, wavelets, nonlinear approximation, image processing and numerical methods for PDE. 